\title{
SOME STUDIES ON CAPILLARIA PHILIPINENSIS AND ITS MYSTERIOUS TRIP FROM PHILIPPINES TO EGYPT (REVIEW ARTICLE) By
}

\author{
REFAAT M.A. KHALIFA AND RAGAA A. OTHMAN \\ Department of Medical Parasitology, Faculty of Medicine, Assiut University \\ (e-mail correspondence: rkhalifa_eg@yahoo.com)
}

\begin{abstract}
Capillaria philippinensis is a mysterious parasite and intestinal capillariasis is a mysterious disease. It is now more than half a century since the discovery of the first case in Philippines without answering many questions concerning the parasite's taxonomy, morphology, life cycle, diagnosis, pathology, clinical symptoms, mode of transmission as well as how it was transported to Egypt and how it started to spread and progressed in most Egyptian Governorates; particularly those of Middle Egypt. This article is a trial to overview all these aspects of the parasite.
\end{abstract}

Key words: Egypt, Capillaria philipinensism, Egypt, comments, recommendations.

\section{Introduction}

The intestinal capillariasis caused by Capillaria philippinensisis a life-threatening disease in humans that causes severe enteropathy (Cross, 1998). The outcome of the disease may be fatal if untreated in due time (Abd-ElSalam et al, 2012). Small freshwater and brackish-water fish are the source of infection and probably fish-eating birds the reservoir host (Cross, 1998). Although more than 250 Capillaria species have been found in fish, amphibians, reptiles, birds and mammals, only 3 species have been found in humans: $C$. philippinensis, C. hepatica and C. aerophila (Eucoleusaerophilus). Reports of human infections with $C$. hepatica, C. aerophila are rare, but reports of $C$. philippinensis infections are increasing and appear to be spreading geographically (Cross, 1992).

The first human case of intestinal capillariasis was reported in the Philippines in 1963 (Chitwood et al, 1964) while the first record of the disease in Thailand was in 1973 (Pradatsundarasar et al, 1973), then more and more cases were detected from both Philippines and Thailand (Sanpakit et al., 1974; Bhaibulaya, 1975; Cross and Bhaibulaya, 1983). Now more than 2,000 cases of intestinal capillariasis have been reported from the Philippines and Thailand, with sporadic cases were reported from Japan (Mukai et al,1983), Korea(Lee et al,1993; Hong et al,1994), Taiwan(Chen et al, 1989, Bair et al,2004, Lu et al,2006), India Kang et al,1994; Vasantha et al, 2012), Iran (Hoghooghi-Rad et al,1987; Rokni, 2008), Egypt (Youssef et al,1989; Mansour et al,1990, Khalifa et al,2000), Indonesian in Italy(Chichino et al,1992), Egyptians in the United Arab Emirates (El-Hassan and Mikhail, 1992; Austin et al, 1999) and Spain (Dronda et al, 1993).

The first outbreak was in a small village in Thailand in 1981 involving 20 patients and 9 deaths. Most of the cases were adults who were over 20 years of age and $80 \%$ of them habited in the same household with a wrong belief of man to man transmission (Kunaratanapruk et al, 1981). Kunaratanapruk et al. (1983) reported that 100 cases of $C$. philippinensis infection had occurred from 1979 to 1981 . Out of them 15 cases died. Later on other case records were re-ported (Benjanuwattar et al, 1990; Chunlertrith et al, 1992; Sangcha et al, 2007).

No doubt, Capillaria philippinensis is a mysterious nematode parasite and intestinal capillariasis is a mysterious disease. It is now about half a century since the discovery of the first case of the disease in Philippines without answering many questions con- 
cerning the parasite's taxonomy, morphology, life cycle, diagnosis, pathology, clinical symptoms, mode of transmission as well as how it was transported to Egypt and how it started to spread and progressed in most Egyptian governorates; particularly those of Middle Egypt. This article is a trial to overview all these aspects of the parasite. Classification and Taxonomy: According to Chitwood et al. (1968) this parasite belongs to Phylum Nematoda Class Adenophorea, Subclass Enoplia, Order Trichocephalida, Family Capillariidae, Genus Capillaria, species philippinensis. On basis of the inaccurate original description given by Chitwood et al. (1968), Moravec (1982) assigned this parasite provisionally to Anochotheca LopezNeyera, 1947 whereas Anderson (1992) without giving a reason named it Colodium philippinensis. Until recently, the species have generally been reported as Capillaria philippinensis in the medical literature (e.g. Hong et al, 1994; Kang et al, 1994; Vilairatauna, 1994; Anis et al, 1998; Hwang, 1998), but Moravec (2001) redescribed the parasite and found his description fully corresponding that of Paracapillaria, Mendonaca, 1963 as refined by Moravec (1982) that included calliparids of fishes, amphibians and reptiles. As compared to the known Paracapillaria spp known from cold-blooded hosts, $C$. philippinensis is unique in that its females may produce free $1^{\text {st }}$ stage larvae besides normal thick-walled unembryonated eggs. All Paracapillaria spp. are known to produce only unembryonated thick-shelled eggs except Paracapillaria rhamdiae which is a stomach parasite of catfishes in Mexico that may lay eggs containing already formed larvae, but no hatched larvae were observed in uterus (Moravec et al, 1995). Moravec (2001) in a key form divided the genus Paracapillaria into three subgenera according to the females being oviparous or larviparous and adults being in worm blooded vertebrates or cold blooded fishes, amphibians and reptiles. The first subgenus was Crossicapillaria (females may produce larvae; adults in warm-blooded vertebrates; larvae in fishes). Sukontason et al. (2006), Nunez et al. (2010) accepted the classification and named it $P$. Crossicapillaria philippinensis. In the present authors' opinion, these differences are not sufficient to create a new genus or subgenus and we should not mix between human capillarids and those of birds, fishes, reptiles and amphibians as the latter parasites have different morphology, mode of transmission and life cycles. Moreover, $C$. philippinensis is the name given to the parasite by the majority of medical parasitologists.

Description of the parasite: Although $C$. philippinensis has been extensively studied over the past 50 years, the only existing description of this nematode is that originally made by Chitwood et al. (1968). Chitwood et al. (1964) described the parasite from specimens collected at autopsy from the first person known to have the infection and in material obtained from several subsequent autopsies. More specimens were examined by other investigators, and the initial findings were confirmed. As most of the laboratory investigators used to find eggs, larvae and adults in the patient's stools, they should be familiar with the detailed morphological features of all the stages of the parasite.

According to Moravec (2001), Attia et al. (2012): Male: Length 2.162-3.114 $\mu \mathrm{m}$, maximum width $30-36 \mu \mathrm{m}$. Entire esophagus $1.170-1.646 \mu \mathrm{m}$ long (53-57\% of body length). Muscular esophagus measuring 138$177 \mu \mathrm{m}$. Stichosome 1.029-1.484 $\mu \mathrm{m}$ long (15-19\% of body length). Posterior end of body rounded, provided with well-developed membranous bursa, supported by 2 rather wide digital lateral projections, not reaching to posterior margin of bursa, projections directed posteriorly in lateral view and curved to median line in ventral view. One pair of large round postanal papillae present at base of caudal projections. Spicule 411468um in length, 6-12; 4-5; 3-4um in width 
at anterior end, middle part; posterior end respectively; its anterior end somewhat expanded; posterior end rounded; covered with very long spineless sheath (about 400um). Female: Length 2.870-3.971 $\mu \mathrm{m}$, maximum width at the posterior body part $36-48 \mu \mathrm{m}$. Length of entire esophagus 1.224$1.659 \mu \mathrm{m}$, representing $42-47 \%$ of body length, muscular esophagus $120-180 \mu$ long,

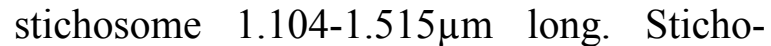
cytes on the posterior portion appeared somewhat larger than those on the anterior portion. Vulva located $24-36 \mu \mathrm{m}$ posterior to the esophagus. The uterus contained one row of either thin- or thick-shelled eggs with defined or ill-defined embryos. Posterior end rounded, and the anus subterminal. Larvae: These stages were first satisfactorily described (Chitwood et al,1968) as follows: L1 is the smallest with a double row of stichocytes and esophagus about $4 / 5^{\text {th }}$ the body length; L2 is 417-550 um in length with double row of stichocytes in the esophagus which is approximately $2 / 3^{\text {rd }}$ the body length, genital column starts to appear; L3 is $1.25 \mathrm{~mm}$ in length, most of the stichocytes are in one column and oral spear apparent, anterior genital column almost complete and posterior one beginning to develop. L4 started the differentiation of the future sex, but differ from adults in size and body proportions and sclerotization of the spicule in males and vaginal development in females. No other detailed description of the larvae was given up till now, except that reported by El-Dib et al. (1999a) who described the $1^{\text {st }}$ larval stage (130-150 u with esophagus more than three quarters of body length and formed of a double layer of stichocytes) but found that the exact demarcation between other different larval stages was not clear. Their description was satisfactory and documented by clear pictures while Moravec (2001) described the free larvae in uterus to be measuring 156$183 \mu \mathrm{m}$ long and $6-9 \mu \mathrm{m}$ wide, with both ends wide; giving no details of the larval contents and stage of development. As larvae represent an important diagnostic stage, laboratory staff should be aware of their structure. So, it is easy to differentiate them from Strongyloides stercoralis larvae which have rhabditiform esophagus.

Eggs: Peanut-shaped with flattened bipolar plugs and striated shells (Zhigang et $a l, 2012)$. They contain either a single cellstage embryo or larvae. An inexperienced laboratory worker may confuse them with Trichuris trichiura eggs which are barrelshaped and have prominent mucoid bipolar plugs (Saichua et al, 2008). According to Cross (1992), Anderson (2000), Moravec (2001) and Attia et al. (2012), there are two types of C. philippinensis eggs: I- The thickshelled eggs: peanut-shaped and had a yellowish-brown color, measuring40-48 $\mathrm{x}$ 17-20 $\mu \mathrm{m}$ with inconspicuous flattened bipolar plugs measuring 2-3.6 x 9-12 $\mu \mathrm{m}$. The wall thickness is $2-3 \mu \mathrm{m}$. Eggs usually contain a single cell stage embryo that filled most of the egg. Some eggs have a slipper or kidney shaped appearance (Khalifa et al, 2000). II- The thin-shelled eggs: peanutshaped measuring 38-45.6 x18-20 $\mu \mathrm{m}$. They are translucent or yellowish in color having single cell-stage embryos or gradually maturating larvae with two characteristically rounded mucoid plugs protruding from their poles. III- Khalifa et al. (2000) added the abnormally swollen eggs: lacking one or both mucoid plugs which appeared unembryonated (unfertilized) and contained degenerated cells or refractile granules that partially or completely filled the inner space of the egg. Swollen thin-shelled eggs with a smooth surface and non-apparent polar plugs at each end were also detected (Anderson, 2000; Moravec, 2001; Attia et al, 2012).

The size of both the thick and the thinshelled eggs detected by Attia et al. (2012) was smaller than that found by Moravec (2001) but was slightly larger than those found by Cross (1992) and Khalifa et al. (2000). In general, the thin-shelled eggs were smaller than the thick-shelled eggs (Moravec, 2001; Attia et al, 2012). Sukonta- 
sonet al. (2006) using SEM described both thick- and thin-shelled eggs. Two distinct morphological shapes of pea-nut-shaped thick-shelled eggs were detected, and these consisted of the typical elongated egg and the swollen egg. Moreover, an intermediateshaped egg that appeared to have a partial beam-like network on its surface was observed, but this shape was not observed in the SEM study of Attia et al. (2012). No doubt, SEM added some ultrastructural details to egg morphology, but these did not seem to be of importance in the routine laboratory egg identification.

Life cycle: The life cycle of $C$. philippinensis was proposed (Cross, 1992) while its complete cycle was given in experimental studies, and may be either indirect (involving an intermediate host) or direct; complete in one host (Saichua et al, 2008).

Indirect life cycle: Fish-eating birds which harbor adults in their intestines, shed embryonated eggs in their feces. When engulfed by uninfected fish, larvae are recovered from their intestines. When these fishes are fed to uninfested birds, larvae develop into adults in their intestinal tract. Larvae recovered from the fish also developed into adults when experimentally fed to gerbils or monkeys (Bhaibulaya et al, 1979). Naturally infested fish (Hypseleotris bipartita and Apagon sp.) and birds (Ixobrychus sp.) have also been found. Humans become infected when they eat raw or undercooked whole small fish, which have the infective larvae in their intestinal tract. While the natural host range is not known, experimental infections of several fishes, including Cyprinus carpio (Common Carp), Puntius gonionotus (Java Barb), Rasbora borapetensis (Red-tailed Raspora), Eleotris melanosoma (Broad-head Sleeper), Ambassis commersoni and Apagon sp., with C. philippinensis eggs yielded infective larvae. Experimental infections of several birds, including Amaurornis phoenicurus White breasted waterhen), Ardeola bacchus (Chinese pond heron), Nycticorax nycticorax
(Black-crowned night heron), Bubulcus ibis (Cattle Egret=Abo Kerdan), Ixobrychus sinensis (Yellow Bittern), Gallinula chloropus (Common Moorhen=swamp chicken), and Rostratula benghalensis (Greater painted Snipe), with larvae yielded mature adults (Saichua et al, 2008).

There was failure to infect laboratory rats from embryonated eggs resulting from study done by Cross $(1990 ; 1992)$ and Khalifa et al. (2000). An experimental infection of fish Oreochrois nilotica nilotica with eggs and/ or larvae was attempted in Egypt by El-Dib and Doss (2002) and Attia et al. (2012) without success. The local Egyptian fishes surveyed for nematode larvae recorded only other capillarids (Capillaria yamaguti and C. fischi (Tadros and Mahmoud, 1986). According to Moravec (2001), fish-eating birds may not be natural hosts for the parasite and in his opinion; the natural definitive hosts of $C$. philippinensis remain obscure. The present authors agree with that opinion and recommend future studies to be done to explore the exact life cycle of the parasite and to find out the final and intermediate hosts of the parasite in Egypt which are unknown up till now.

Cross et al. (1978) succeeded in experimental infection of Mongolian gerbil (Merionis unguicalatus) and short-lasting infection in a very small number of wild rats (Rattus norvegicus and Rattu srattus) in which they never found natural infection. Thus, they recommended to use Mongolian gerbils for keeping the laboratory infection for parasitic studies by serial passages from gerbil to another. Furthermore, El-Shazly et al. (2008) in a cross-sectional survey of helminthes in 271 rodents of Rattus norvegicus, Rattus rattus frugivorous, Rattus $r$. alexandrines and Mus musculus from Dakahlia and Menoufia Governorates, reported a total of 24 species of helminthes; $C$. philippinensis was not among them.

Direct life cycle: Researchers also found that feeding just a few dozen larvae from the intestines of fish to Mongolian gerbils 
(Meriones unguiculatus) or monkeys (Macaca sp.) led to infection with thousands of adult worms through autoinfection. The experimentally infested monkeys never developed any clinical symptoms, even during the prolonged active infestations (seeming to act as reservoir hosts). Of several rodents tested, only Mongolian gerbils developed severe symptoms due to infestation and died (Saichua et al, 2008). In the present author's opinion, autoinfection is different from direct life cycle which mean the possibility of person to person infection; a condition which was never recorded in cases of human capillariasis.

Clinical manifestations and pathogenesis: Intestinal capillariasis is a life-threatening disease in humans that causes severe enteropathy (Cross, 1998). Intestinal capillariasis patients usually present with watery diarrhea, weight loss, abdominal pain, borborygmi, muscle wasting, weakness, edema and laboratory examination shows low levels of potassium and albumin in blood, and malabsorption of fats and sugar. Those patterns may result from $C$. philippinensis secretion of a proteolytic substance or direct penetration of the intestinal wall that causes cellular injury and dysfunction (Saichua et $a l, 2008)$. Several studies showed intestinal pathological findings in $C$. philippinensis infection because the worms can be found in the lumen, the mucosa, or in the crypts of Lieberkuhn in the human jejunum. The most common pathological features are the thickening of the intestinal wall, the prominence of the vessels, the atrophy of the crypts, and flattening of the villi (Sangcha et al, 2007). Thus, the destruction of the intestinal cell membrane may interrupt nutrient absorption that causes weight loss in intestinal capillariasis patients. Moreover, the intestinal cells' destruction may lead to fluids, proteins and electrolytes loss because those intestinal cells are dysfunctional and cannot control body fluids and electrolytes balance which results in a low level of potassium and albumin in the blood of patients ( $\mathrm{Lu}$ et al, 2006; Saichua et al, 2008).

According to Attia et al. (2012), in SEM; the unexplained tight obscure membrane that covered nearly the entire surface of the adult worms may have been the result of an intense inflammatory reaction by the immune system of the host. Bunches of intestinal villi that covered the cuticle and plugged the mouth opening may be related to the mucosal penetration that is commonly initiated by the worm and that manifests as severe diarrhea. In their study, each of the cases presented with various degrees of intestinal manifestations that included intermittent abdominal pain, borborygmi, chronic (continuous or intermittent) diarrhea lasting several weeks, and marked weight loss (up to $10 \mathrm{~kg}$ ). In addition, these patients had various degrees of painless lower leg edema, which is corresponding with the results of Ahmed et al. (1999) and Lu et al. (2006).

El-Karaksyet al. (2004) reported two infected Egyptian sisters from El-Menia Governorate in which the previous clinical pictures were detected in addition to the presence of hyponatremia. Lu et al. (2006) found that when a diagnosis was finally made, some cases already showed clinical symptoms of septic shock. If the infection remains untreated, it leads to death. Attia et al. (2012) found many potential early cases of this infection needed to be differentiated from other diseases with identical clinical manifestations, such as Crohn's disease, TB enteritis, and various intestinal malignancies. As a result, these cases were evaluated using long list of sophisticated measures that were not diagnostic for intestinal capillariasis but did reveal important features that improved knowledge of the pathogenicity of this parasitic disease. These additional diagnostic measures included a full blood panel, abdominal ultrasonography (revealing pleural effusion and ascites in some patients), upper endoscopies (gastroduodenoscopies that revealed malabsorption) and histopathological examinations of the 
duodenal and jejunal biopsies (revealing atrophic and flattened villi, inflammatory cell infiltration, and numerous sections of the adult worm in the epithelial layer). It is worth mentioning that up till now, the presence of mild or asymptomatic cases (which is usually observed in almost all intestinal parasites) is absolutely unknown in cases of $C$. philippinensis infections.

Diagnosis: The diagnosis of intestinal capillariasis is commonly delayed and generally requires the experience of medical parasitologists and the physicians should be particularly sensitized to the consumption of raw fish which should be asked during anamnesis and made aware of zoonosis which are transmitted through raw or insufficiently cooked fish (Dronda et al, 1993; Zhigang et al, 2012). Reports of delayed diagnoses for more than few months have been reported in Japan and India (Nawa et al, 1988), Korea (Lee et al, 1993; Vasantha et al, 2012), Egypt (El-Dib and Doss, 2002). The areas where C. philippinensis has spread, the number of afflicted countries and the infected cases may far exceed what one knows so far (Lu et al, 2006). The majority of the patients had a history of consuming raw or uncooked fishes, and this is a crucial factor of intestinal capillariasis infection.

The diagnosis depends mainly on:

1- Stool examination for detection of eggs, larvae and/or adult worms. Unembryonated eggs are peanut-shaped with flattened bipolar plugs and a striated shell. Multiple stool samples may be needed for early diagnosis in some cases as the eggs are shed sporadically and irregularly in feces (Cross, 1992). The presence of Charcot-Leyden crystals in the stool samples of the patients supported the diagnosis, and number of these crystals is usually correlated with the intensity of the the infection (Attia et al, 2012). Larvae may be found in the stools but are difficultly diagnosed as those of $C$. philippinensis (Cross, 1992).This needs accurate and comprehensive description of the different Capillaria larval stages, as also juvenile and adults may be encountered in the same stool sample.

2- Detection of coproantigen may be used to overcome the false negative diagnosis of C. philippinesis at time of absence of eggs in stool. El-Dib et al. (2004) designed C. philippinensis coproantigen to determine its diagnostic value using two different ELISA techniques. This antigen was able to detect anti-Capillaria antibodies in the sera of infected cases at the same OD level produced with Capillaria crude worm antigen using indirect ELISA technique. $C$. philippenensis coproantigen did not crossreact with sera from patients with schistosomiasis mansoni, fascioliasis or strongyloidiasis at 1:100 serum dilutions.

3- Immunodiagnosis may be a supplementary tool which helps to detect $C$. philippinensis infection which may be useful for screening persons who have intestinal capillariasis-like symptoms before discovering Capillaria eggs or larvae in their stool. Thus, Banzon et al. (1975) used Capillaria obsignata in IHA test, Abdel-Rahman et al. (2005) used egg antigen and coproantigen in diagnosis by immuoblot and Intapan et al.(2006, 2010) used Trichinella spiralis soluble antigen in an immunoblot analysis and ELISA test respectively for diagnosis of capillariasis cases where eggs and/or larvae are absent in stools. All cases showed positive results.

4- Small intestinal aspiration or biopsy may be necessary to confirm $C$. philippinensis infection (Cross, 1991; Lu et al, 2006). Gastroduodenoscopy in a 13-year-old boy from central Thailand showed the eggs in a jejunal biopsy (Wongsawasdi et al, 2002). Besides, jejunal mucosal biopsy and microscopic jejunal content examinations were successfully used to identify intestinal capillariasis in a 27-year-old Thai man who had negative repeated stool tests (Sangcha et $a l, 2007)$. El-Dib and Doss (2002) reported one Egyptian case which was diagnosed by abdominal laparoscopy. Kang et al. (1994), 
Hong et al. (1994) and Wongsawasdi et al. (2002) had cases definitively diagnosed based on histopathological findings on panendoscopic jejunal biopsy specimens. Histopathological examination of duodenal biopsies indicated heavy cellular infiltration around the sectioned adult worms and larvae (Lee et al, 1993; Abd-El-Salam et al, 2012).

Transmission: The eating habits of people are responsible for the transmission of human intestinal capillariasis. Populations in the Philippines where intestinal capillariasis is endemic have unique eating habits in that they prefer to eat a variety of sea foods uncooked. In other countries, consumption of raw fish has been associated with most infections (Cross, 1992). Since a number of species of freshwater fish have been experimentally infected with $C$. philippinensis and some fish in the Philippines were found naturally infected with larval forms of the parasite (Cross and Bhaibulaya, 1983), it is believed that the means of transmission of the disease is by eating uncooked fish. Cross (1992) reported that the parasite has not been found in any area where populations do not eat raw fish. Lu et al. (2006) believed that consuming raw or uncooked fishes is a crucial factor of intestinal Capillaria infection. However, nearly all Egyptian patients denied having consumed any raw or undercooked fishes. The present authors propose that the infection may occur when the ingested food is contaminated by the uncooked visceral contents of infested fish. Therefore, whether patients have consumed raw or uncooked fish ought to be taken into consideration but should not be the basis for ruling out the possibility of intestinal capillariasis. Khalifa et al. (2000) stated that it would be very difficult to follow the method of transmission, as infective larvae are usually found in the intestine and not in muscles of infected fish intermediate host, meaning that infection only after swallowing of intact fish (with intact intestine), which is not a habit in Egypt.
Migratory fish-eating birds are considered potential natural hosts, and their migratory habits are considered responsible for dissemination of the parasite to widely separated parts of the world (Austin et al, 1999). Bird droppings along the flyways could easily disperse the eggs into water bodies, where fish become infected. Birds and humans eating such fish would subsequently become infected (Zhigang et al, 2012).

The present Senior Author had supervised several M.Sc and M.D Theses throughout the last three decades on endoparasites of fresh water fishes and wild birds from Aswan, Qena, El-Minia and Assiut; amphibians from Sohag and reptiles from Assiut and is now leading a team work for the study of endoparasites of Red Sea fishes without reporting capillarid adults or larvae in all these hosts. Capillarid larvae were also not recorded in Ardeola goliath (El-Naffaret al, 1980), Burhimus oedinemussahare (Khalifa et al, 1989) and amphibians (Khalifa et al., 1998). Thus, many unanswered questions arise: what is the method of infection of $C$. philippinensis in Egypt while its intermediate and final hosts are still unknown? How the parasite could initiate and completed its life cycle in our country? Why the parasite is more prevalent in some Middle Egyptian governorates?

Intestinal capillariasis in Egypt: As many Egyptian authors usually publish their researches in unavailable local or university periodicals, this review may be lacking some of these studies. The incoming works are the available studies: It is noteworthy to mention that infection has taken a serious situation in Egypt with continuous detection of new indigenous cases and it became the country with the highest number of reported cases outside the endemic areas (El-Dib and Doss, 2002). The first Egyptian case was reported by Youssef et al. (1989) in a 41year-old female from Cairo; the second case was a 38-year-old female living in Lower Egypt (Mansour et al, 1990). Many subsequent cases have been reported from 
different parts of Egypt including Cairo (ElDib et al, 1992; 1999) and Menouf City (Mansour et al, 1998; Anis et al, 1998; Austin et al, 1999b). Ahmed et al. (1999) reported four cases; three from NagaaHammady City and one from Beni Suif. Khalifa et al. (2000) recovered the first case from Assiut and El-Karkasyet al. (2004) detected two infected sisters in El-Minia City.

It was demonstrated that the severity of intestinal capillariasis cases has grown in Egypt and that the parasite still surprisingly spreading more or less in most of the Egyptian Governorates. Thus (El-Dib and Doss, 2002) who reported 44 cases; 37 females and 7 males: 8 from Cairo, 2 from Menouf, 2 from Banha, 2 from El-Giza, 2 from Al-Fayoum, 9 from Beni-Suif, 17 from El-Minia, 1 from both Assiut and Qena (30 cases from Middle and Upper Egypt). Moreover, in Assuit, Attia et al. (2012) reported the first series of 21 patients with C. philippinensis infections outside the endemic area which suggests that the parasite has spread across Egypt and may also indicate the presence of suitable natural intermediate and final hosts. Their data seems to answer the question posed by Ahmed et al. (1999) as to whether $C$. philippinensis infection will spread further across Egypt.

It remains unclear how this disease, which is endemic in the Far East, began appearing in Egypt and other Middle East countries, although it is possible that some of the imported species of fresh water fish from the Far East were infected. It has been suggested that some fish-eating migratory birds may acquire this infection by consuming infested fish along migratory pathways and that the birds could then excrete eggs to infect fish in other remote areas (El-Dib and Doss, 2002). However, this theory is disproved because infected wild birds of the Far East migrate to Europe, and it would be unlikely that they could have transmitted this parasite to Egypt. Furthermore, if this theory was true, the northern parts of Egypt should be more greatly affected than Upper Egypt (Ahmed et al, 1999). Additional hypotheses have suggested that imported fish are the more likely source of this infection in Egypt, as most of the frozen fish sold at Egyptian markets are imported from the Far East. However, because this fish is frozen at very low temperatures for a lengthy amount of time before consumption makes this theory difficult to accept. The study of Attia et al. (2012) included 19 middle-aged females; most of them were housewives which may be related to their role in the preparation and cooking of the fish for the family, as they would have greater exposure to raw infested fish than would males. The actual prevalence of this parasite is likely greater than was estimated, but physician incognizance and technician inexperience at clinical laboratories as well as the availability of over-the-counter anti-helminthic and the intestinal antiseptics have hindered its identification. Therefore, the present authors emphasized that clinicians should remain highly alert to recognize the signs of this treatable infection. Furthermore, the number of cases of infection with this parasite may far exceed that estimated for Assuit Governorate and other Middle Egyptian governorates. Actually, Parasitology research laboratory, Assiut University Teaching Hospital added 2 newly discovered non notified cases within the last two months (personal communication).

Control: Strategy to fight the disease consists of not eating raw fish, promoting a health education program and the early diagnosisis necessary to minimize and/or eradicate $C$. philippinensis infection. The health education campaign aims to promote the consumption of cooked fish and to avoid defecation into a water resource in order to eliminate the infection. Early diagnosis is necessary for treating patients, especially improving experience of laboratory technicians and multiple stool examination (Saichua et al, 2008). The control measures 
could be reasonable in Far East countries where the parasite's life cycle is known and where populations used to consume raw fish as a traditional habit, but in Egypt, control measures could not be planned without knowing how the parasite completed its life cycle as well as its mode of transmission.

\section{Conclusion}

Capillaria philippinensis has been mysteriously introduced to Egypt since 1989 and started to spread insidiously and gradually from one governorate to another; so as now the parasite has been notified throughout almost the whole country. Since that time (about a quarter of a century); parasitologists could not get answers to all the mysterious questions concerning this parasite. In spite of the continuous efforts of research workers, we did not found any convincing replies to how the parasite was introduced to Egypt, its mode of transmission in absence of known intermediate and final hosts. Hence, it is highly recommended that a team work of Biologists, Zoologists, Medical and Veterinary Parasitologists should work together; hand in hand to try to explore the mysterious natural intermediate and final hosts in which the parasite completes its life cycle in Egypt as a milestone to our knowledge of its method of transmission and future plans to its control.

\section{References}

Abdel-Rahman, SM, Moneib, ME, Sha-hin, MS, Abdel Aziz, LA, 2005: Immuno-diagnosis of Capillaria philippinensis by western blot using coproantigen and egg antigen. El-Minia Med. Bull. 16, 2: 9-17.

Abd-Elsalam, N, Hassany, SM, Medhat, M,et al, 2012: Capillaria philippinensis: A cause of chronic diarrhea in Upper Egypt. J. Arab. Soc. Med. Res. 7:10-3

Ahmed, L,El-Dib, N, El-Borey, Y, Ibrah-im, M, 1999: Capillaria philippinensis: An emerging parasite causing severe diarrhea in Egypt. J. Egypt. Soc. Parasitol. 29, 2:483-93.

Anderson, RC, 1992: Nematode Parasites of Vertebrates: Their development and transmission. CAB Internat.Willingford.UK.
Anderson, RC, 2000: Nematode Parasites of Vertebrates: Their Development and Transmission. Second edition; Oxon, UK: CABI Publishing.

Anis, MH, Shafik, H, Mansour, NS, Moo- dy, A, 1998: Intestinal capillariasis as a cause of chronic diarrhea in Egypt. J. Egypt. Soc. Parasitol. 28:143-7.

Attia, AH, Tolba, ME, Yones, DA, Bakir, HY, et al, 2012: Capillaria philippinensis in Upper Egypt: Has it become endemic? Am. J. Trop. Med. Hyg. 86, 1:126-33.

Austin, DN, Mikhail, MG, Chiodini, PL, Murray-Lyon, LM, 1999:Intestinal capillariasis acquired in Egypt. Eur. J.Gastro-enterol. Hepatol. 11:935-6.

Bair, MJ, Hwang, KP, Wang, TE et al, 2004: Clinical features of human intestinal capillariasis in Taiwan. Wld. J. Gastro-enerol. 15, 6:3391-3.

Banzon, TC, Lewert, RM, Yogore, MG, 1975: Serology of Capillaria philippinensis: reactivity of human sera to antigen prepared from Capillaria obsignataand other helmi-nthes. Am. J. Trop. Med. Hyg. 24, 2:256-63.

Benjanuwattar, T, Morakote, N, Somb-oon, P, Sivasomboon, $B$, 1990: Intestinal capillariasis: indigenous cases from Chiang Mai and Phayao provinces, Thailand. J. Med. Assoc. Thai. 73:414-7.

Bhaibulaya, MB, 1975: Studies on Ca-pillaria philippinensis in Thailand. 1: Epidemiologic Survey. Report of Thailand Nat. Res. Council: 11.

Bhaibulaya, M, Indra-Ngarm, S, Ananthapruti, M, 1979: Freshwater fishes of Thailand as experimental intermediate host of Capillaria philippinensis. Int. J. Parasitol. 9, 2:79-157.

Canlas, BC, Cabrera, BD, Davis,U, 1967: Human intestinal capillariasis. II. Patho-logical features. Acta Med. Philipp. 4:84-91.

Chen, CY, Hsieh, WC, Lin, JT, Lu, MC, 1989: Intestrinal capillariasis: A report of a case. J. Taiwan Med. Assoc. 88: 617-20.

Chichino, G, Bernuzzi, AM, Bruno, A,et al. 1992: Intestinal capillariasis acquired in Indonesia: a case report. Am. J. Trop. Med. Hyg. 47:10-12.

Chitwood, MB, Velasquez, C, Salazar, N G, 1964: Physiological changes in species of 
Capillaria (Trichuroidea) causing a fatal case of human intestinal capillariasis. Proc. $1^{\text {st }}$ Int. Congr. Parasitol. Rome.

Chitwood, MB, Valesquez, C, Salazar, N G, 1968: Capillaria philippinensissp n. (Nematoda: Trichinelloidea) from intestine of a man in the Philippines. J. Parasitol. 54: 348-71.

Chunlertrith, K, Mairiang, P, Sukeepaisarnjaroen, W, 1992: Intestinal capilla-riasis: a cause of chronic diarrhea and hypoalbuminemia. Southeast Asian. J. Trop. Med. Pub. Hlth. 23:433-6.

Cross, JH, 1990: Intestinal capillariasis. Parasitol. Today 6:26-8.

Cross, JH, 1992: Intestinal capillariasis. Clin. Microbiol. Rev. 5:120-9.

Cross, JH, 1998: Capillariasis. Palmer, Soulsby, Simpson, eds. Zoonoses: Biology, Clinical Practice, and Public HealthControl. $1^{\text {st }}$ edition. New York: Oxford University Press.

Cross, JH, Bhaibulaya, M, 1983: Intestinal capillariasis in the Philippines and Thailand. In: N. Croll and J. H. Cross (ed.), Human Ecology and Infectious Diseases.Academic Press, Inc., New York.

Cross, JH, Banzon, T, Singon, C, 1978: Further studies on Capillaria philippinensis: development in the Mongolian gerbil. J. Parasitol. 64, 2:208-13

Dronda F, Chaves F, Sanz A, Lopez-Velez R, 1993: Human intestinal capillariasis in an area of non-endemicity: Case report. Clin. Infect. Dis. 17:909-12.

El-Hassan, ES, Mikhail, WE, 1992: Malabsorption due to Capillaria philippinensis in an Egyptian in Dubai, United Arab Emirates. Trans. Roy. Soc. Trop. Med. Hyg. 86:79-81.

El-Dib, NA, Doss, WH, (2002): Intestinal capillariasis in Egypt: Epidemiological background. J. Egypt. Soc. Parasitol. 32, 1: 145-54.

El-Dib, NA, Farrag, AJ, Salama, HM, et al, 1992: A new case of intestinal capilla-riasis in Egypt. J. Trop. Med. Hyg. 2:75-6.

El-Dib, N, Ahmed, J, Al-Arousy, M, et al, 1999a: Parasitological aspects of Capillaria philippinensis recovered from Egyptian patients. J. Egypt. Soc. Parasitol. 29, 1:139-47.

El-Dib,NA, Ahmed, L, EL-Boraey, Y, et al, 1999b: Capillaria philippinensis: an emerging parasite causing severe diarrhea in Egypt. J. Egypt. Soc. Parasitol. 29, 1:483-93.

El-Dib, NA, Sabry, MA, Ahmed, JA, et al, 2004: Evaluation of Capillaria philippinensiscoproantigen in the diagnosis of infec-tion. J. Egypt. Soc.Parasitol. 34, 1:97-106.

El-Karaksy, H, El-Shabrawi, M, Mohsen, N, 2004: Capillaria philippinensis a cause of fatal diarrhea in one of two infected Egyptian sisters. J. Trop.Pediatr.50:57-60.

El-Naffar, MK, Khalifa, R, Sakla, AA, 1980: Parasitofauna of the Egyptian aquatic birds: IITrematode parasites of the giant heron (Ardeola goliath) in Assiut Gover-norate. J. Egypt. Soc. Parasitol. 10:107-16.

El-Shazly, AM, Awad, SI, Azab, MS, Elsheikha, HM, Abdel-Gawad, AG, Morsy, TA, 2008: Helminthes of synanthropicro-dents (Rodentia: Muridae) from Dakahlia and Menoufia, Egypt. J. Egypt. Soc. Para-sitol. 38, 3:727-40.

Hoghooghi-Rad, N, Maraghi, J, Naren-Sadek, A, 1987: Capillaria philippinensis infection in Khoozestan Province, Iran: a ca-se report. Am. J. Trop. Med. Hyg. 37:135-7.

Hong, S, Kim, Y, Choe, G, et al, 1994: Two cases of intestinal capillariasis in Korea. Korean J. Parasitol. 32, 1:43-8.

Hwang, KP, 1998: Human intestinal capillariasis (Capillaria philippinensis) in Tai-wan. Zhonghua Minguo.Xiao.ErKe. Yi Xue Hui Za Zhi. 39:82-85.

Intapan PM, Maleewong W, Sukeepaisarnjaroen W, Morakote N, 2006: Potential use of Trichinella spiralis antigen for sero-diagnosis of human capillariasis Philip-pinensis by immune blot analysis. Parasitol. Res. 98:227-31.

Intapan, PM, Malewong, W, Sukeepaisrangaroen, W, Morakote, N, 2010: An enz-yme linked immunosorbent assay as scree-ning tool for human intestinal capillariasis. Southeast J. Trop. Med. Pub. Hlth. 41, 2: 298-305.

Kang, G, Mathan, M, Ramakrishna, BS, et al, 1994: Human intestinal capillariasis: First report from India. Trans. R. Soc. Trop. Med. Hyg. 88:204-6.

Khalifa, R, Monib, ME, Sakla,AA, 1989: On the diplostomatid parasites from the bird Burhinus oedienemus saharae(Saharan stone 
curlew) in Assiut, Upper Egypt. Assiut Med. J. 13:135-44.

Khalifa, R, Abdel-Kader, AI, Mostafa, N, 1998: On the development and transmission of Paracosmocerca mucronata(Nematoda: Cosmocercidae) in amphibians under experimental conditions. J. Union Arab. Biol. Cairo, (Zool.) 10:321-32.

Khalifa, R, Sakla, A, Hassan, A, 2000:Capillaria philippinensis-a human intestinal nematode newly introduced to Upper Egypt. Helminthol. 37:23-7.

Kunaratanapruk,S, Iam-Ong, S, Chatsirimongkol, C, 1981:Intestinal capillariasis: The first epidemic in Thailand. Ramathibodi Med. J. 4:209-13.

Kunaratanapruk, S, Iam-Ong S, Chatsirimongkol $\mathrm{C}$,et al,1983: Intestinal capilla-riasis: A report of 100 cases. Ramathibodi Med. J. 6:253-8.

Lee, SH, Hong, ST, Chai, JY, et al, 1993: A case of intestinal capillariasis in the Re-public of Korea. Am. J. Trop. Med.Hyg. 48:542-6.

Lu, LH, Lin, MR, Choi, WM, et al, 2006: Human intestinal capillariasis (Capillaria philippinensis) in Taiwan. Am. J. Trop. Med. Hyg. 74:810-13.

Mansour, NS, Anis, MH, Mikhail, EM 1990: Human intestinal capillariasis in Egypt. Trans. R. Soc. Trop. Med. Hyg. 84: 114-6.

Moravec, F, 1982: Proposal of a new systematic arrangement of nematodes of the fam- ily Capillaridae. Folia Parasitol. 29:119-32.

Moravec, F, 2001: Redescription and systematic status of Capillaria philippinensis, an intestinal parasite of human beings. J. Parasitol. 87:161-4.

Moravec, F, Gonzles-Solis, D, VargasVazques, J, 1995: Paracapillaria rhamdiae sp. N. (Nematoda: Capillaridae) from Rhamdia guatemalensis (Pisces) in Yucatan, Mexico. Parasite 2:235-8.

Mukai, T, Shinmizu, S, Yamamoto, M, et al, 1983: A case of intestinal capillariasis. Jpn. Arch. Int. Med. 30:163-9.

Nawa, Y, Imai, JI, Abe, T, Abe, T, et al, 1988: A case of intestinal capillariasis. The second case found in Japan. Jpn. J. Parasitol. 37:113-8.

Nunez, FA, Espino, F, Astencio-Rodiquez, AI, et al, 2010: First finding of human infection with Paracapillaria (Crossicapil- laria) philippinensis (Chitwood, Velazquez and Salazar, 1968) in Cuba. Rev. Cubana Med. Trop. 62, 2:125-9.

Pradatsundarasar, A, Pecharanond, K, Chintanawongs, Ungthavorn, P, 1973: The first case of intestinal capillariasis in Thailand. Southeast Asian. J. Trop. Med. Pub. Hlth.4:1314.

Rokni, MB, 2008: The present status of human helminthic diseases in Iran. Ann. Trop. Med. Parasitol. 122, 4:283-95.

Saichua, P, Choosak, N, Natthawut, K, 2008: Human intestinal capillariasis in Tha-iland. Wld. J.Gastroenterol. 14:506-10.

Sangcha, A, Wongsaensook, A, Kularbk- aew, C, et al, 2007:The endoscopic-pa-thologic findings in intestinal capillariais: A case report. J. Med. Assoc. Thai. 90:175-8.

Sanpakit, S, Suksungvol, S, Bhaibulaya, M, 1974: Intestinal capiliariasis from Sara-buri Province, Thailand: Report on the se-cond case. J. Med. Assoc. Thai. 57:458-60.

Sukontason,KL, Sukontason, K, Pia-ngjai, SR, 2006: Ultrastructure of eggs Paracapillaria (Capillaria) philippinensis and evidence related to its life cycle. Micron37:87-90.

Tadros, G, Mahmoud, ML, 1968: Capi-llaria yamagutti sp. n. From the Nile fish Bargus bayad. J. Vet. Sci. UAR 5:133-42.

Wongsawasdi, L, Ukarapol, N, Lertprasertsuk, N, 2002: The endoscopic diagnosis of intestinal capillariasis in a child: A case report. Southeast Asian J. Trop. Med. Pub. Hlth33: 7302.

Vasantha, PL, Girish, N, Leela, KS, 2012: Human intestinal capillariasis: A rare case report from non-endemic area (Andhra Pradesh, India). Indian J. Med. Microbiol. 30:236-9.

Vilairatana, P, 1994: Capillariasis with chronic intestinal pseudo-obstruction. South-east Asian J. Trop. Publ. Hlth.25:600-2.

Youssef, FG, Mikhail, EM, Mansour, NS, 1989: Intestinal capillariasis in Egypt: A ca-se report. Am. J. Trop. Med.Hyg.40:195-6.

Zhigang, F, Yongdong, $\mathrm{H}$, Shiyun $\mathrm{Q}$, et al, 2012: Serious diarrhea with weight loss caused by Capillaria philippinensis acquired in China: A case Report. BMC Research Notes 5, 1:554. 